\title{
Farmers' Exposure to Climate Hazards and Reforestation in Selected African Villages: An Endogenous-Switching Regression Model
}

\section{Tolulope Olayemi Oyekale}

Federal University of Agriculture Abeokuta

Abayomi Oyekale ( $\sim$ asoyekale@gmail.com)

North-West University

\section{Research article}

Keywords: Deforestation, Climate Hazards, Tree Planting, Endogenous Switching Regression

Posted Date: August 29th, 2019

DOI: https://doi.org/10.21203/rs.2.12127/v1

License: (c) (1) This work is licensed under a Creative Commons Attribution 4.0 International License.

Read Full License 


\section{Abstract}

Background: Deforestation remains a serious concern for Africa's economic development and global climatic stability. Emphases are now placed on promoting some essential adaptive and mitigation strategies among smallholder farmers. This paper analyzed the effect of exposure to climate-related hazards on tree planting among smallholder farmers in nine selected African countries. The data were from baseline surveys which were conducted by the CGIAR's research programme on Climate Change, Agriculture and Food Security (CCAFS). The included countries were Burkina Faso, Ethiopia, Ghana, Kenya, Mali, Niger, Senegal, Tanzania and Uganda. Data were analyzed with Endogenous Switching regression considering the endogeneity potentials of climate-hazard exposure. Results: The results showed that Uganda and Ethiopia had the highest average numbers of tree planting with 1.082 and 1.000 respectively, while Senegal (89.86\%), Kenya (87.77\%), Burkina Faso (82.86\%) and Ethiopia (82.86\%) had the highest exposure to climate-related hazards. Endogenous Switching regression results showed that climate hazard exposure was truly endogenous going by statistical significance of the Wald Chi Square test $(p<0.05)$ and it was significantly influenced by female household headship, perception of more droughts, floods and low ground water. The number of tree that were planted increased significantly $(p<0.05)$ with climate hazard exposure, degraded land areas, asset indices and residence in East Africa, while it reduced with female household headship. In addition, Average Treatment Effect (ATE) result indicated that an average household will plant 0.745 trees more when it had been previously exposed to climate shocks while Average Treatment Effect on the Treated (ATET) revealed that an average household that was exposed to climate hazards would plant 0.54 more trees than it would if it had not been exposed to hazards. Conclusion: The major implication of the findings is that without having previously experienced some climatic adversities, farmers may not see the need to engage in tree planting as a mitigating strategy. It was concluded that many farmers had been affected by climate-related shocks and efforts to safeguard future climate through tree planting should be gender sensitive and concentrated among previously affected farmers.

\section{Background}

Deforestation is one of the major environmental problems in the world today (Yosef et al., 2018). In Africa, significant heterogeneity exists in the available stock of forest resources (Aleman et al., 2017). Specifically, while forestland areas in Central Africa seem to have increased since the turn of 20th century, West and East African regions are notably the hotspots for deforestation with net forestland losses of about $83 \%$ and $93 \%$, respectively. Moreover, beyond the role of acting as carbon sink, some interrelationships exist between the stock of forestland and climatic parameters. Deforestation influences the stability of climatic parameters as a result of persistent emission of carbon dioxide into the atmosphere via some cleared forestland (Bodegom et al., 2009). It is also critical to understand the impact that some climatic hazards like droughts, flooding and general reduction in the volume of rainfall could have on development of forest resources. Without some effective environmental policies and other 
regulatory mechanisms, deforestation possesses significant potentials to truncate climatic stability, thereby predisposing farming households to some other climate-related shocks.

Climate change is a problem that currently ranks among the topmost environmental hazards bedeviling the world today (Powledge, 2012). The World Meteorological Agency (WMA) (2012) indicated that between 1980 and 2005, the world witnessed about 7500 natural disasters that accounted for death of more than 2 million people and resulted in economic losses estimated at above US \$1.2 trillion. It was further emphasized that these disasters are largely witnessed in the form of flash floods, severe droughts, tropical cyclones, landslides, wildfires, stormy rainfalls, windstorms, extreme surge in temperature and outbreak of pests and diseases. Therefore, numerous global warning signals that are being received from climatic hazards today are portfolio of evidences that the world should be properly prepared to take drastic actions to reverse current climatic disasters or be fully prepared to be diametrically entrapped by the consequences of such obnoxious negligence.

Powledge (2012) emphasized that climate change is among the foremost and momentous human development issues given current climatic trends and predictions, as well as gross inadequacy of accessible mitigating activities. It is calamitous to note that some previous international negotiation platforms for reducing the impacts of climate change on the world's developing countries are yet to fathom some sustainable solutions. This is quite alarming given that such activities are essential for realizing some climate-related goals as highlighted in the thirteenth Sustainable Development Goal (SDG). Although the 2015 United Nations Climate Change Conference (UNCCC) sought to achieve "a binding and universal agreement on climate, from all the nations of the world" (Food and Environment, undated), commitments from global partners in fast-tracking development initiatives that are required for reducing green house gas emission are sometimes lacking or at best misplaced. Therefore, understanding the mechanisms for adapting to climate change in developing countries is of critical relevance to post-2015 development agendas, given the diversity in the contents and contexts of interrelated development issues that have been reemphasized in the seventeenth SDGs.

Furthermore, besides the different adaptation methods that are being introduced to farmers, policy makers have realized the need to encourage some mitigation strategies to forestall some future climatic hazards. One of such recommendations is direct involvement in tree planting in order to combat some environmental consequences of desertification among which climate change is notable (Betts, 2000; Claussen et al., 2001; Arora and Montenegro, 2011). The underlying notions of reemphasizing reforestation as a way of curtailing some negative consequences of climate change through some mitigation procedures cannot be overemphasized. Specifically, conservation of trees is potentially able to promote carbon sequestration to the tune of approximately $10 \%$ of the global carbon sink potentials, which would offset any warming of the biosphere in about 6 years (Yosef et al., 2018).

Besides the scientific studies that attest to positive environmental potentials of reforestation, socioeconomic studies on correlates of involvement in tree planting hold some potentials for evolving some policy changes that would influence human pro-environment behaviours. In some previously 
conducted studies, Hannan and Commins (1993) submitted that reforestation decision was motivated by some structural changes within the agricultural landscape such as the size of the farms, engagement with some off-farm employment and level of farm incomes. More specifically, Danquah (2015) used Logistic regression model to analyse the factors influencing farmers' decision to be involved in afforestation programme in Ghana. It was found that security of land tenure rights, land areas owned, previous involvement in tree conservation, household size and cropland areas were the statistically significant factors. Kulindwa (2016) also analyzed the factors influencing tree planting behaviour in Tanzania using the Heckman selection bias modeling. It was found that tree planting was significantly influenced by households' land holdings, tree planting programme awareness, and farmers' age.

Although previous researches have modeled determinants of reforestation, studies linking idiosyncratic exposure of households to climate hazards with involvement in reforestation are scanty. This is the major contribution of this paper, which seeks to extend the scope of modeling reforestation with econometric consideration of endogeneity and selection biasness of households' previous exposure to climatic shocks. This approach promises to produce more reliable results since inability to address endogeneity and selection bias of this variable would compromise some desirable properties of estimated parameters in terms of efficiency, unbiasedness and consistency. In the remaining parts of the paper, we have provided the methods of data collection and analysis, results and discussion and conclusion.

\section{Materials And Methods}

\section{The Study Areas, Data and Sampling Methods}

The data for this study were derived from baseline surveys that were conducted by the CCAFS programme of the CGIAR. The surveys were carried out between 2010 and 2011 in nine African countries. The sampling was implemented with selection of a study site after which seven villages were randomly selected among the listed villages. In all the villages, 140 respondents were sampled with samples distributed in proportion to the number of households within those villages. However, due to some inconsistencies, some questionnaires were discarded, making some sites to therefore have less than 140 respondents. Table 1 presents the distribution of respondents across the selected sites (Mango et al., 2011 Lyamchai, et al., 2011; Desta et al., 2011; Somé et al., 2011; Naab et al., 2011; Diakité et al, 2011; Moussa et al., 2011; Yacine et al., 2011; Mubiru et al., 2012; Kyazze, 2011).

\section{Estimated Model}

An Endogenous-Switching Poisson Regression Approach was adopted for this paper because we considered climate hazard exposure, which is an independent variable to be potentially endogenous within the specified model. In STATA 13, the etpoisson command estimates the parameters of the specified Poisson regression model with one endogenous binary treatment. The treatment-effect is essential because we are dealing with a nonlinear potential-outcome model that assumes some form of correlation between "the unobservables that affect the treatment and the unobservables that affect the 
potential outcome". One basic advantage of this method is its ability to utilize the estimated parameters for computing "the average treatment effect (ATE) and average treatment effect on the treated (ATET)". The estimated models are stated as follows:

$$
\begin{aligned}
& E\left(Y_{j} / X_{i j}, S_{j}, \epsilon_{j}\right)=\operatorname{Exp}\left(X_{i j} \beta_{i}+\alpha S_{j}+\epsilon_{j}\right) \\
& S_{j}=\left\{\begin{array}{c}
1, X_{i j} \mu_{i}+u_{j}>0 \\
0, \text { otherwise }
\end{array}\right.
\end{aligned}
$$

Where $Y_{j}$ denotes the number of trees that have been planted. Also, the $X_{i j}$ are the independent variables which are asset index computed with Principal Component Analysis (PCA) from a set of reported assets in the dataset, own degraded land (ha), female headed household (yes $=1,0$ otherwise), number of income sources, region (East Africa $=1,0$ otherwise), household size, formal education (yes $=1,0$ otherwise), exposure to more droughts (yes $=1,0$ otherwise), exposure to more floods (yes $=1,0$ otherwise), exposure to strong winds (yes $=1,0$ otherwise), exposure to higher salinity (yes $=1,0$ otherwise) and exposure to low groundwater water (yes $=1,0$ otherwise). The treatment variable is $S j$ which is farmers' previous exposure to some form of climatic hazard in the past five years (yes $=1,0$ otherwise).

\section{Results}

\section{Descriptive Statistics of Farmers' Tree Planting and Climate Shock Exposure}

The results in Table 2 present the distribution of the number of tree that were planted by farmers and their exposure to climate shocks. The table reveals that highest average numbers of tree planting were recorded for Uganda and Ethiopia with 1.082 and 1.000 respectively. These are followed by Kenya and Tanzania with 0.971 and 0.907 , respectively. The lowest average numbers of planted trees were in Niger (0.157), Mali (0.376) and Senegal (0.521). Figure 1 also presents the distribution of the total number of trees that were planted by all the farmers. It shows that majority did not plant ant trees, thereby depicting a kind of zero inflated distribution. In addition, the Table presents information on exposure of rural households to climate shocks. It reveals that while farmers from Tanzania the lowest percentage of exposure to climate shocks (48.57\%), Senegal (89.86\%), Kenya (87.77\%), Burkina Faso $(82.86 \%)$ and Ethiopia (82.86\%) had the highest.

\section{Determinants of Climate Shock Exposure and Planted Trees}

The results in Table 3 show the descriptive statistics of variables that were used for the Poisson regression analysis. Table 4 presents the results of the endogenous switching model. The results show that climate hazard exposure is truly endogenous going by statistical significance of the Wald Chi Square test $(p<0.05)$. The correlation between climate hazard exposure errors and the tree planting errors is 
-0.9230. This implies that unobservables that increase tree planting tend to be highly (but negatively) correlated with those been exposed to climate shocks. The etpoisson command in STATA 13 estimates two results. The first is for the treatment, which in this case is climate hazard exposure. The second is for determinants of tree planting with climate hazard exposure taken as an endogenous variable. In this case, we also invoked the command with computation of robust standard error. This implies that the parameters have been purged of any form of heteroscedasticity.

The results in Table 4 show that female headed households had significantly higher probability $(p<0.01)$ of being exposed to climate hazard, when compared with their male counterparts. Perception of more droughts, floods and low ground water by households significantly increased their probability of being affected by climate hazard. The Table also presents the results for determinants of number of trees planted. The results showed that exposure to climate hazards significantly increased the number of trees planted by the farmers $(p<0.01)$. This finding corroborates those results for ATE and ATET that are also presented in Table 4. The estimated ATET of climate hazard exposure on the number of planted trees is 0.54 . This implies that average household that was exposed to climate hazards would plant 0.54 more trees than it would if it had not been exposed to hazards. The results further show that asset index significantly increased tree planting. In addition, as the area of degraded land owned by farmers increased, the number of planted trees also significantly increased $(p<0.01)$. Female headed households planted significantly lower number of trees when compared with their male counterparts. The results in Table 4 further show that farmers with some formal education planted significantly higher number of trees $(p<0.01)$. The results also show that perception of drought and flooding significantly reduced the number trees planted.

\section{Discussion}

The results indicate the high exposure of female headed households to climate hazard. This finding is in line with expectation because female headed households in rural areas can be more vulnerable to poverty, which in turn increases their vulnerability to environmental hazards. The finding is also in line with finding of Suhiyini et al. (2018) who reported that female headed households in Ghana exhibited higher vulnerability to many dimensions of climate induced livelihood vulnerability. Nathaniel et al. (2019) also reported similar finding for some farmers in Nigeria. In some instances, female headed farming households are only eligible to cultivate marginal land of low fertility and have limited access to other production resources (World Bank, 1994). However, in some other studies, it had been reported that even when climate-related hazards are covariate in nature, the degree of impacts or welfare losses by different categories of rural dwellers would differ based on their adaptive capacities (World Bank, 2010).

Furthermore, those farmers that perceived droughts, floods and low ground water were more likely to be affected by climate hazard. These findings are in alignment with expectation. In a study by Dessai and Sims (2010), it was noted that drought is one of the major forms of climate change being perceived by households in England. The implications of droughts on African agriculture are often compounded by the enormity of the population that directly depends on rain-fed agriculture without any form of 
supplementary irrigation (Dalby, 2009; Yaro, 2013). In a study in Ghana, Jarawura (2014) highlighted farmers' understanding on the difference between different environmental extremes. It was found that distinctions were made between situations of excess rainfall and flooding, and between short dry spell and drought.

The farmers that were exposed to climate hazards on the average planted more trees. This is expected given that farmers that were previously exposed to environmental hazards may find it necessary to adopt pro-environmental behaviour. The ATET result further implies that an average household that was exposed to climate hazards would plant 0.54 more trees than it would if it had not been exposed to hazards. Chen et al. (2013) found that individuals that were previously affected by environmental hazards have higher tendencies of engaging in pro-environmental behaviour. In some other studies, it had been noted that the cost of extreme environmental events always compels people to change their behavior (Spence et al., 2011; Whitmarsh, 2008; Kollmuss and Agyeman, 2002). It had also been found that previous exposure to some environmental hazards enhances people's coping and mitigation knowledge, and eventually influences their adaptation capacity (Hamilton et al, 2013; Rudman et al., 2013; Zaval et al., 2014).

The results also indicate that as asset index increases, the number of planted trees increases. This result underscores the role of wealth in pro-environmental behaviour. In some previous studies by Sikor and Baggio (2014) and Duguma and Hager (2010), assets possessed by farmers had been found to have positive impacts on tree planting. In addition, the number of planted trees increased as the area of degraded land owned by the farmers increased. This result is in line with the basic theoretical expectation since land degradation is a pronounced consequence of deforestation. Sustainable management of degraded land often begins with tree planting, or at the least ensuring some possibilities of vegetation covers. This is expected to ensure drastic reduction in the rate of erosion and promotion of soil organic matter composition (Dean, 2017; Bui and Do, 2017).

Households that were headed by males planted more trees when compared with their female counterparts. Although women's roles in land management have been acknowledged in literature, constraints in assessing resources can limit participation of female farmers in forefront land conservation activities. The finding in this study underscores basic limitations that women could face in participating in soil conservation programmes. It also points at the possibility of being resource constrained, thereby limiting their full engagement in soil conservation programmes. However, in a study by Meijer et al. (2014), there was no significant difference between number of trees that were planted across gender in Malawi. It was noted that although male household heads could be the initiator of tree planting, it takes the cooperation and efforts of both couple to ensure survival of trees. This may be associated to the role women could play in timely application of water to young tree plants, especially during dry spells and protecting them from being overcrowded by weeds.

Attainment of formal education increased the number of planted trees. It had been noted that education promotes environmental awareness and prioritization of tree planting for environmental conservation 
(Agea et al., 2009; Agea et al., 2005; Obua et al., 1998). This result is therefore expected, given the role that education could play in understanding and adopting agronomic measures to preserve environment. Similar findings had been reported by Agea et al., (2010) who found that education influenced planting of tree fruit crops in Uganda. In another study, Mekonnen and Damte (2011) found that educational levels of household heads significantly influence tree planting behaviour in Ethiopia. However, a study that was conducted by Kulindwa (2016) found that education was statistically insignificant in influencing tree planting.

Perception of drought and flooding reduced the number trees planted. These results are also expected and they more or less reflect the negative implications that some of the climatic adversities could have for sustainable land use and management. Depending on the genetic composition of the tree, planting trees during periods of prolonged dry spells and drought could be challenging because the so called drought resistant species need considerable period of time to be fully established beyond that threshold where water shortages become inconsequential. Some studies on physiological changes that promote death of trees as a result of drought have highlighted some pernicious threat of climate change (Allen et al., 2015; Gessler et al., 2017).

\section{Conclusion}

This study presents an analysis of the effect of climate hazard exposure on tree planting decision in selected African countries. The econometric procedures allow us to also understand the drivers of smallholder farmers' exposure to climatic hazards. The findings from the study are reechoing some channels of policy actions for addressing reforestation in Africa. The results clearly indicate low involvement in tree planting with average number of planted trees being very small, especially among the farmers in the selected West African countries. It was also found that number of degraded plots of land and attainment of formal education increased tree planting. There is therefore the need for promoting awareness on the benefits of reforestation with emphases on geographical landscapes and farmlands with pronounced land degradation and among illiterate farmers.

Exposure to climate hazards increased number of planted trees. This finding highlights the need to integrate environmental conservation issues within the framework of providing assistances to those affected by climate hazards. There were also some gender factors explaining farmers' exposure to climate hazards an tree planting. There is the need for ensuring gender sensitivity in programmes meant for addressing reforestation given that female farmers may not have access to requisite resources for being fully integrated. Integrating women in pro-environmental programmes would be beneficial for ensuring their full involvement since they are likely to be worst exposed to climate hazards. Asset owned increased the number of planted trees. This is very critical given that deliberate allocation of resources for environmental conservation may poses some challenges to poorest segment of rural population.

\section{List Of Abbreviations}


ATE - Average Treatment Effect

ATET - Average Treatment Effect on the Treated

CCAFS - Climate Change, Agriculture and Food Security

CGIAR - Consultative Group on International Agricultural Research

PCA - Principal Component Analysis

SDG - Sustainable Development Goal

UNCCC - United Nations Climate Change Conference

WMA - World Meteorological Agency

\section{Declarations}

\section{Ethical Approval and Consent to Participate}

All the required ethical clearances and approvals were granted to the CGIAR's research programme on Climate Change, Agriculture and Food Security (CCAFS). The farmers were properly informed about the study and granted their consents to participate before being interviewed.

\section{Consent to Publish}

Not applicable.

\section{Availability of Data and Materials}

The data for this study were obtained from the portal of the CGIAR's research programme on Climate Change, Agriculture and Food Security (CCAFS). The authors were granted the permission to use the data with due acknowledgement of sources.

\section{Competing interest}

The authors do not have any competing interests.

\section{Funding}

The authors did not receive any funding for this study.

\section{Authors' Contributions}

Both authors conceptualized the study. The authors contributed towards analysis of the data and presentation of the results. The authors have read and approved the final version of the manuscript. 


\section{Acknowledgement}

The authors would like to acknowledge the permission that was granted by CCAFS program of the CGIAR to use the dataset.

\section{References}

Agea, J.G., J.Obua, D. Waiswa, C.A. Okia and J. B. L. Okullo (2010). Farmers' Attitude Towards Cultivation of Indigenous Fruit Trees in Adwari Sub-County, Lira District, Uganda.

Agea, J.G., Nansereko, S., Obua, J., Waiswa, D., Buyinza, M. and Yikii, F. 2009. Attitudes of Out-of-School Youths towards Tree Planting Activities in Central Uganda: A Case Study of Masaka. Discovery and Innovation 21(1\&2): 111-118.

Agea, J.G., Obua, J., Namirembe, S. and Buyinza. M. 2005. Agroforestry potential of AcaciaSenegal in the rangelands of Luwero and Nakasongola districts. Uganda Journal of Agricultural Sciences 11: 34-39.

Aleman, J.C., Jarzyna, M.A. and Staver, A.C. (2017). Forest extent and deforestation in tropical Africa since 1900. Nature Ecology \& Evolution 2, 26-33.

Arora, V. K. \& Montenegro, A. Small temperature benefits provided by realistic afforestation efforts. Nature Geoscience 4, 514-518 (2011).

Betts, R. A. Offset of the potential carbon sink from boreal forestation by decreases in surface albedo. Nature 408, 187-190 (2000).

Bodegom, V., Jan, A., Savenije, H. and Wit, M. (eds). (2009). Forests and Climate Change: adaptation and mitigation. Tropenbos International, Wageningen, The Netherlands. xvi + 160 pp.

Bui, X. D. and V. Q. Do, "Applying universal soil loss equation (USLE) to estimating soil erosion at Lam Son headwater catchment," Journal of Forestry Science and Technology, vol. 5, 2017, 
http://vnuf.edu.vn/documents/4400543/5135893/8.Bui. Xuan.Dung.pdf.

Chen, X., M. N. Peterson, V. Hull, C. Lu, D. Hong and J. Liu (2013). How Perceived Exposure to Environmental Harm Influences Environmental Behavior in Urban China. Ambio. 2013 Feb; 42(1): 52-60.

Claussen, M., Brovkin, V. \& Ganopolski, A. Biogeophysical versus biogeochemical feedbacks of large-scale land cover change. Geophysical research letters 28, 1011-1014 (2001).

Dalby, S. (2009). Security and Environmental Change. Cambridge: Polity Press.

Danquah, J.A. (2015). Analysis of factors influencing farmers' voluntary participation in reforestation programme in Ghana. Forests, Trees and Livelihoods. 24(3):176-189.

Dean (2017). How can tree planting can prevent soil erosion? Available online: https://socratic.org/questions/how-can-tree-planting-can-prevent-soil-erosion (Accessed 6th February 2019).

Dessai, S. and Sims, C (2010) Public perception of drought and climate change in southeast England, Environmental Hazards, 9:4, 340-357, DOI: 10.3763/ehaz.2010.0037

Desta S, Tezera S, Gebru, G, P.Kristjanson. 2011. Summary of Baseline Household Survey Results: Borana, Ethiopia. CGIAR Research Program on Climate Change, Agriculture and Food Security (CCAFS). Copenhagen, Denmark. Available online at: http://ccafs.cgiar.org/resources/baseline-surveys

Diakité, L.., K. Sissoko, R. Zougmoré, B. Traoré, M. Amadou, A.S. Moussa, W. Forch, C. Garlick, S. Ochieng, P. Kristjanson, P.K. Thornton, 2011. Summary of household baseline survey results - Cinzana, Mali. CGIAR Research Program on Climate Change, Agriculture and Food Security (CCAFS).Copenhagen, Denmark. Available online at: www.ccafs.cgiar.org 
Duguma, A.L., Hager, H., 2010. Woody plants diversity and possession, and their future prospects in small-scale tree and shrub growing in agricultural landscapes in central highlands of Ethiopia. SmallScale Forestry, 9(2010): 153-174.

Food and Environment (undated). Universal agreement on climate change - not too far! Available at: http://www.foodandenvironment.com/2015/02/universal-agreement-on-climate-change.html (Accessed 31st December 2017).

Gessler, A., Schaub, M., McDowell, N.D. The role of nutrients in drought-induced tree mortality and recovery. New Phytologist, 214: 513-520 doi:10.1111/nph.14340

Hamilton, L.C.; Stampone, M.D. Blowin' in the wind: Short-term weather and belief in anthropogenic climate change. Weather Clim. Soc. 2013, 5, 112-119.

Hannan, D.F. and Commins, P. 1993. Factors Affecting Land Availability for Afforestation. Economic and Social Research Institute, Dublin.

Jarawura, F.X. (2014). Perceptions of drought among rural farmers in the Savelugu district in the northern Savannah of Ghana. Ghana Journal of Geography, 6:102 - 120.

Kollmuss, A.; Agyeman, J. Mind the gap: Why do people act environmentally and what are the barriers to pro-environmental behavior? Environ. Educ. Res. 2002, 8, 239-260.

Kulindwa, Y.J. (2016). Key factors that influence households' tree planting behaviour. Natural Resource Forum. 40(1-2):37-50.

Kyazze, F.B., Kristjanson P. 2011. Summary of Baseline Household Survey Results: Rakai District, South Central Uganda. CGIAR Research Program on Climate Change, Agriculture and Food Security (CCAFS). Copenhagen, Denmark. Available online at: http://ccafs.cgiar.org/resources/baseline-surveys 
Lyamchai C, Yanda P, Sayula G, Kristjanson, P. 2011. Summary of Baseline Household Survey Results: Lushoto, Tanzania. CGIAR Research Program on Climate Change, Agriculture and Food Security (CCAFS). Copenhagen, Denmark. Available online at: www.ccafs.cgiar.org.

Mango, J., A. Mideva, W Osanya and A. Odhiambo. 2011. Summary of Baseline Household Survey Results: Lower Nyando, Kenya. CGIAR Research Program on Climate Change, Agriculture and Food Security (CCAFS). Copenhagen, Denmark. Available online at: www.ccafs.cgiar.org.

Meijer S, Catacutan D, Sileshi G W, Nieuwenhuis M (2014). The role of gender in household decision making on tree planting: A case study from Malawi. Poster presented at World Congress on Agroforestry. World Agroforestry Centre and University College Dublin.

Mekonnen, A., Damte, A., 2011. Private tree and household assets and determinant of tree-growing behaviour in rural Ethiopia. EfD Discussion Paper Series 11-14. Resources for the Future and Environmental for Development, Washington, DC and Gothenburg

Moussa, B., K. Sissoko, R. Zougmoré, K. Dieye, M. Amadou, A.S. Moussa, W. Forch, C. Garlick, S. Ochieng, P. Kristjanson, P.K. Thornton 2011. Résumé des résultats des enquêtes de base niveau ménage - site de Fakara, Niger. Programme de recherche du CGIAR sur le Changement Climatique, I'Agriculture et la Sécurité Alimentaire (CCAFS). Copenhague, Danemark. Disponible en ligne sur www.ccafs.cgiar.org

Mubiru, D.N, Kristjanson, P. 2012. Summary of Baseline Household Survey Results: Hoima District, West Central Uganda. CGIAR Research Program on Climate Change, Agriculture and Food Security (CCAFS). Copenhagen, Denmark. Available online at: http://ccafs.cgiar.org/resources/baseline-surveys

Naab, J.B. , K. Sissoko, R. Zougmoré, B. Traoré, M. Amadou, A.S. Moussa, W. Forch, C. Garlick, S. Ochieng, P. Kristjanson, P.K. Thornton, 2011. Summary of Baseline Household Survey Results: Lawra, Ghana. CGIAR Research Program on Climate Change, Agriculture and Food Security (CCAFS).Copenhagen, Denmark. Available online at: www.ccafs.cgiar.org 
Nathaniel E. Urama, Eric C. Eboh \& Anthony Onyekuru (2019) Impact of extreme climate events on poverty in Nigeria: a case of the 2012 flood, Climate and Development, 11:1, 27-

34, DOI: $10.1080 / 17565529.2017 .1372267$

Obua, J., Banana, A. Y. and Turyahabwe, N. 1998. Attitudes of local communities towards forest management practices in Uganda: the case of Budongo forest reserve. Commonwealth Forestry Review 77 (2): $113-118$

Powledge, F. (2012). Scientists, Policymakers, and a Climate of Uncertainty: Can research gain a foothold in the politics of climate change? BioScience, 62(1): 8-13, https://doi.org/10.1525/bio.2012.62.1.3

Rudman, L.A.; McLean, M.C.; Bunzl, M. When truth is personally inconvenient, attitudes change: The Impact of extreme weather on implicit support for green politicians and explicit climate-change beliefs. Psychol. Sci. 2013, 24, 2290-2296.

Sikor, T., Baggio, J.A., 2014. Can smallholders engage in tree plantations? An entitlements analysis from Vietnam. World Development, 64: S101-S112.

Somé,L., K. Sissoko, R. Zougmoré, B. Traoré, M. Amadou, A.S. Moussa, W. Forch, C. Garlick, S. Ochieng, P.Kristjanson, P.K. Thornton, 2011. Summary of household baseline survey results -

Tougou, Burkina Faso. CGIAR Research Program on Climate Change, Agriculture and Food Security (CCAFS).Copenhagen, Denmark. Available online at: www.ccafs.cgiar.org

Spence, A.; Poortinga, W.; Butler, C.; Pidgeon, N.F. Perceptions of climate change and willingness to save energy related to flood experience. Nat. Clim. Chang. 2011, 1, 46-49.

Suhiyini I. Alhassan, John K.M. Kuwornu, Yaw B. Osei-Asare, (2018) "Gender dimension of vulnerability to climate change and variability: Empirical evidence of smallholder farming households in Ghana", International Journal of Climate Change Strategies and Management, https:// doi.org/10.1108/IJCCSM10-2016-0156 
Whitmarsh, L. Are flood victims more concerned about climate change than other people? The role of direct experience in risk perception and behavioural response. J. Risk Res. 2008, 11, 351-374.

World Bank (1994). Reversing the Spiral - The Population, Agriculture, and Environment Nexus in SubSaharan Africa. Washington DC.

World Bank (2010), Economics of Adaptation to Climate Change: Social synthesis Report, 1818 H Street NW, Washington DC.

World Meteorological Organization (2012). Natural disasters and climate monitoring. Earth Observation, No. 1. Available online: http://itunews.itu.int/en/2074-Natural-disasters-and-climatemonitoring-.note.aspx (retrieved 11 August 2018).

Yacine, N., K. Sissoko, R. Zougmoré, K. Dieye, M. Amadou, A.S. Moussa, W. Forch, C. Garlick, S. Ochieng, P. Kristjanson, P.K. Thornton 2011. Summary of household baseline survey results - Kaffrine, Senegal. CGIAR Research Program on Climate Change, Agriculture and Food Security (CCAFS).Copenhagen, Denmark. Available online at: www.ccafs.cgiar.org

Yaro, J. A. (2013). The perception of and adaptation to climate variability/change in Ghana by smallscale and commercial farmers. Regional Environmental Change, 13, 1259-1272.

Yosef, G., Walko, R., Avisar, R., Tatarinov, F., Rotenberg, E., and Yakir, D. (2018). Large-scale semi-arid afforestation can enhance precipitation and carbon sequestration potential. Scientific Reports. 8:996.

Zaval, L.; Keenan, E.A.; Johnson, E.J.; Weber, E.U. How warm days increase belief in global warming. Nat. Clim. Chang. 2014, 4, 143-147.

\section{Tables}


Table 1: Distribution of Respondents Across the Selected Sites

\begin{tabular}{|l|c|c|c|c|}
\hline Country & Region/District & No. of Villages & Respondents & \% of Total \\
\hline Burkina Faso & Tougou & 7 & 140 & 10.01 \\
\hline Ethiopia & Borana & 7 & 140 & 10.01 \\
\hline Ghana & Lawra-Jirapa & 7 & 140 & 10.01 \\
\hline Kenya & Nyando & 7 & 139 & 9.94 \\
\hline Mali & Cinzana & 7 & 141 & 10.09 \\
\hline Niger & Fakara & 7 & 140 & 10.01 \\
\hline Senegal & Kaffrine, & 7 & 138 & 9.87 \\
\hline Tanzania & Lushoto & 7 & 140 & 10.01 \\
\hline Uganda & Hoima and Rakai & 14 & 280 & 20.03 \\
\hline Total & & 70 & 1,398 & 100.00 \\
\hline
\end{tabular}

Table 2: Distribution of the average number of trees planted and proportions affected by climatic shocks

\begin{tabular}{lccc}
\hline Site/Country & \multicolumn{2}{c}{ Trees Planted } & Shock exposure (\%) \\
\hline \multirow{4}{*}{ Burkina Faso } & 0.821 & 1.152 & 82.86 \\
Ethiopia & 1.000 & 0.000 & 82.86 \\
Ghana & 0.643 & 0.769 & 80.71 \\
Kenya & 0.971 & 1.123 & 87.77 \\
Mali & 0.376 & 0.722 & 68.09 \\
Niger & 0.157 & 0.499 & 48.57 \\
Senegal & 0.522 & 0.998 & 89.86 \\
Tanzania & 0.907 & 1.187 & 46.43 \\
Uganda & 1.082 & 1.187 & 71.43 \\
Total & 0.756 & 0.993 & 72.96 \\
\hline
\end{tabular}

Table 3: Descriptive Statistics of Variables for Regression Analysis 


\begin{tabular}{lcccc}
\hline Variable & Mean & Std. Dev. & Min & Max \\
\hline Tree planted & .7560801 & .9931128 & 0 & 4 \\
Asset index & -.0009514 & 1.813834 & -2.55 & 23.37 \\
Own degraded land & .6660944 & 1.565919 & 0 & 20 \\
Female headed household & .1144492 & .3184700 & 0 & 1 \\
No of income sources & 1.989986 & 1.473182 & 0 & 7 \\
Region & .5000000 & .5001789 & 0 & 1 \\
Household size & 9.481402 & 7.956801 & 1 & 85 \\
Formal education & .8283262 & .3772316 & 0 & 1 \\
More droughts & .2782546 & .4482999 & 0 & 1 \\
More floods & .0522175 & .2225449 & 0 & 1 \\
Strong winds & .0715308 & .2578016 & 0 & 1 \\
Higher salinity & .0107296 & .1030635 & 0 & 1 \\
Low ground water & .0386266 & .1927723 & 0 & 1 \\
Climate hazard in past five years & .7296137 & .4443183 & 0 & 1 \\
\hline
\end{tabular}

Table 4: Results of Endogenous Switching Regression and Computation of Treatment Effects 


\begin{tabular}{|c|c|c|c|c|c|c|c|}
\hline \multirow[b]{2}{*}{ Variable } & \multicolumn{3}{|c|}{ Climate Shock Exposure } & \multicolumn{4}{|c|}{ Tree Planting } \\
\hline & Coef. & Std. Err. & $\mathrm{z}$ & Coef. & $\exp (b)$ & Std. Err. & $\mathrm{z}$ \\
\hline Asset index & 0.0501 & 0.0270 & 1.86 & $0.0639 * * *$ & 1.0660 & 0.0168 & 3.80 \\
\hline Own degraded land & 0.065 & 0.0349 & 1.88 & $0.0725^{* * *}$ & 1.0751 & 0.0258 & 2.81 \\
\hline Female headed & $0.3410^{* * *}$ & 0.1245 & 2.74 & $-0.2942 * * *$ & 0.7451 & 0.1052 & -2.80 \\
\hline No of income sources & 0.0437 & 0.0267 & 1.64 & 0.0102 & 1.0103 & 0.0269 & 0.38 \\
\hline Region & -0.1154 & 0.0927 & -1.24 & $0.9310 * * *$ & 2.5370 & 0.0964 & 9.65 \\
\hline Household size & 0.0030 & 0.0058 & 0.51 & 0.0032 & 1.0033 & 0.0052 & 0.62 \\
\hline Formal education & -0.1113 & 0.1027 & -1.08 & $0.2961 * *$ & 1.3447 & 0.1182 & 2.51 \\
\hline More droughts & $0.3113^{* * *}$ & 0.0926 & 3.36 & $-0.1891 * *$ & 0.8277 & 0.0881 & -2.15 \\
\hline More floods & $0.6190 * * *$ & 0.2143 & 2.89 & $-0.3173^{* *}$ & 0.7281 & 0.1584 & -2.00 \\
\hline Strong winds & $-0.5456 * * *$ & 0.1561 & -3.49 & -0.0482 & 0.9529 & 0.1458 & -0.33 \\
\hline Higher salinity & 0.7791 & 0.4688 & 1.66 & -0.1932 & 0.8244 & 0.2062 & -0.94 \\
\hline Low groundwater water & $0.5821 * *$ & 0.2611 & 2.23 & 0.3350 & 1.3979 & 0.1827 & 1.83 \\
\hline Climate hazard asfive years & - & - & - & $1.1112^{* * *}$ & 3.0379 & 0.2505 & 4.44 \\
\hline Constant & $0.4883^{* * *}$ & 0.1283 & 3.81 & $2.0062^{* * *}$ & 0.1345 & 0.2384 & -8.42 \\
\hline ATE & .74479 & .1778907 & & & & & \\
\hline ATET & .53963 & $.074314^{* * *}$ & & & & & \\
\hline \multicolumn{8}{|l|}{ Diagnostic parameters } \\
\hline /athrho & $-1.6087 * * *$ & 0.5716 & -2.81 & & & & \\
\hline /lnsigma & $-0.5209 * * *$ & 0.1931 & -2.70 & & & & \\
\hline rho & -0.9230 & 0.0847 & & & & & \\
\hline sigma & 0.5940 & 0.1147 & & & & & \\
\hline Wald Chi2(13) & $175.36^{* * *}$ & & & & & & \\
\hline Number of obs & 1398 & & & & & & \\
\hline
\end{tabular}

\section{Figures}




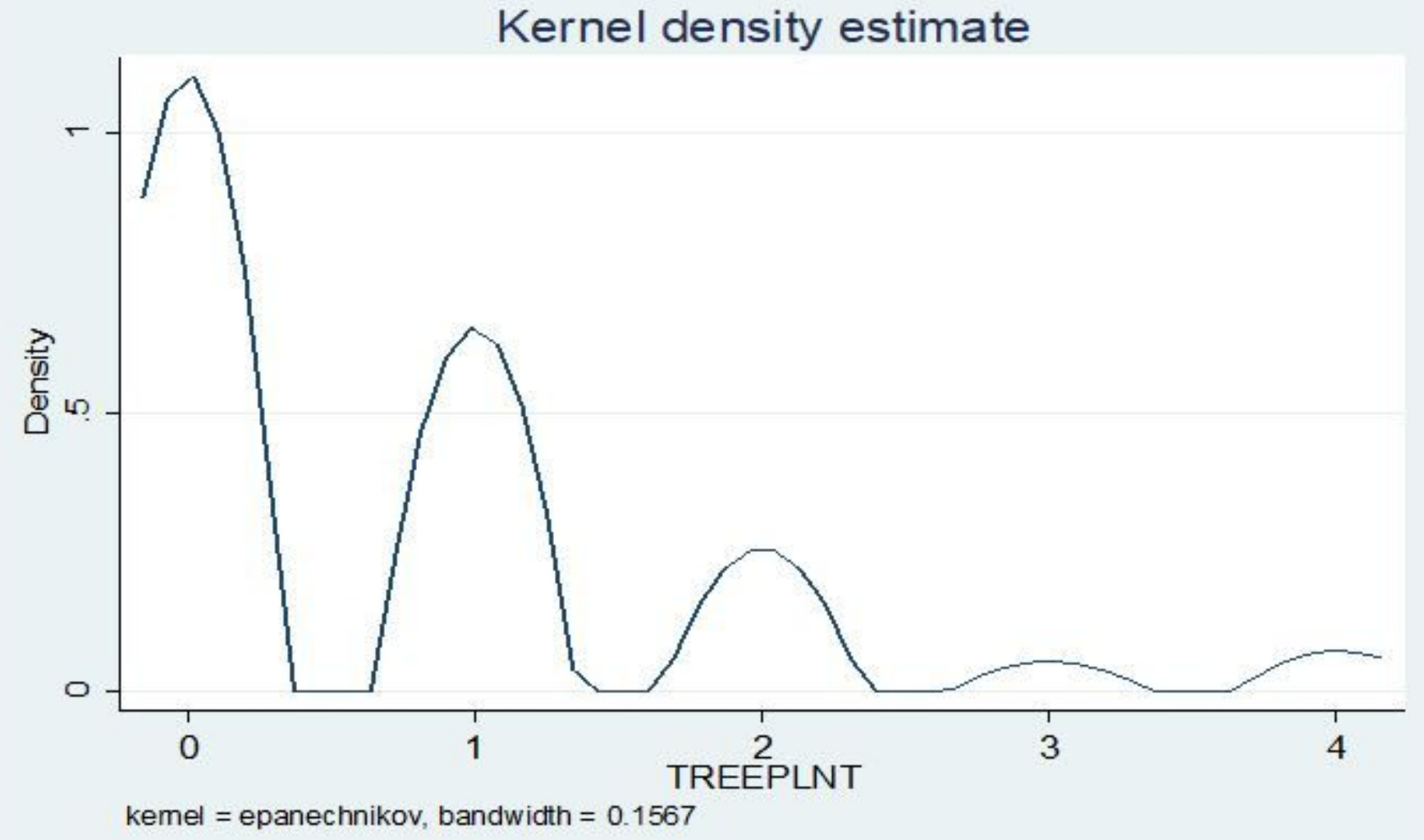

Figure 1

Kernel Density Distribution of Number of Trees Planted 